Check for updates

Cite this: Mater. Adv., 2020, 1,1354

Received 9th May 2020,

Accepted 8th July 2020

DOI: 10.1039/d0ma00292e

rsc.li/materials-advances

\title{
Identifying suitable ionic liquid electrolytes for Al dual-ion batteries: role of electrochemical window, conductivity and voltage $\dagger$
}

\author{
Surya Sekhar Manna, (D) Preeti Bhauriyal (D) and Biswarup Pathak (D)*
}

\begin{abstract}
Identifying suitable ionic liquid (IL) electrolytes with the desirable electrochemical properties remains a primary challenge for rechargeable Al dual-ion batteries (DIBs). Furthermore, it is also important to investigate how the size and structure of the cation determine the suitability of IL electrolytes in Al DIBs. In this work, with the help of first principles calculations, we have investigated a series of imidazoliumbased room temperature ionic liquids (RTILs) by varying the alkyl substituents along with the pyrrolidinium electrolytes and molten salts such as urea/AlCl 3 and acetamide/AlCl 3 . The suitability of the electrolytes is analyzed on the basis of three criteria: electrochemical window (ECW), ionic conductivity and voltage. The HOMO-LUMO positions of the electrolytes with respect to the Fermi positions of the respective electrodes can determine whether the electrolytes ( $\mathrm{EMIM-AICl}, \mathrm{PMIM}-\mathrm{AlCl}_{4}, \mathrm{BMIM}^{-} \mathrm{AlCl}_{4}$ and urea- $\mathrm{AlCl}_{4}$ ) can perform as more suitable electrolytes, furnishing higher cationic reduction and anionic oxidation stability. Further, our calculated ionic conductivity data favor the usage of the EMIM-AICl 4 electrolyte as it shows the highest ionic conductivity $\left(14.1 \mathrm{mS} \mathrm{cm}{ }^{-1}\right.$ ) amongst the considered electrolytes (3.4-12.4 mS cm $\mathrm{cm}^{-1}$ ). However, these considered electrolytes do not show drastically different effects on the average voltage, furnishing quite similar values in the range of 2.21-2.46 V, which are in accordance with their corresponding experimentally reported voltages. Overall, from these three criteria, we could certainly validate why $\mathrm{EMIM}-\mathrm{AlCl}_{4}$ is the most experimentally used electrolyte in $\mathrm{Al}$ DIBs. Moreover, our study also predicts $\mathrm{PMIM}_{-} \mathrm{AlCl}_{4}$ to be a suitable ionic liquid electrolyte for Al DIBs, as it shows a higher ECW value (4.7 V), a moderate ionic conductivity $\left(12.4 \mathrm{mS} \mathrm{cm}^{-1}\right)$ and a suitable theoretical voltage $(2.28 \mathrm{~V})$ along with exhibiting a higher experimental coulombic efficiency compared to $\mathrm{EMIM}-\mathrm{AlCl}_{4}$.
\end{abstract}

\section{Introduction}

Renewable energy sources like wind and solar power have been prominently used to fulfill electricity demand as green energy systems. However, the storage of energy from these systems is challenging as the generated electricity is intermittent in nature. ${ }^{1-3}$ Whereas, efficient electrical energy storage devices must get a constant supply of electricity (power storage backup) and load leveling as well as grid energy storage for future application. $^{4,5}$ Presently, owing to their high voltage and outstanding power density, Li-ion batteries are the most popular

Discipline of Chemistry, Indian Institute of Technology (IIT) Indore, Indore, Madhya Pradesh 453552, India. E-mail: biswarup@iiti.ac.in

$\dagger$ Electronic supplementary information (ESI) available: The supporting information file contents are different orientation structures of imidazolium-based electrolytes, cathodic and anodic limiting potentials of the considered electrolytes, NBO charge analysis of the EMIM-AlCl 4 and $\mathrm{BMP}_{4} \mathrm{AlCl}_{4}$ electrolytes, physical properties (density and viscosity) of the considered electrolytes and ionic radii of cations and anions of all the electrolytes. See DOI: 10.1039/d0ma00292e amongst metal-ion batteries, but the main concerns that limit their application are the excessive cost and associated safety concerns mainly coming from thermal runaway events. ${ }^{6,7}$ Therefore, initialization of new battery systems using more abundant natural resources, such as Na-ion, ${ }^{8-10} \mathrm{Mg}$-ion $^{11-13}$ and $\mathrm{Al}-$ ion $^{14-17}$ batteries, is urgently needed in the field of stationary batteries for achieving uninterrupted electricity. Among these emerging trends of batteries, the $\mathrm{Al}$ battery is the most predominant one owing to: (i) its low-cost, lowflammability and high abundance of $\mathrm{Al}$ metal, and (ii) the involvement of the three electron redox couple that provides a high gravimetric capacity. ${ }^{18-21}$ For the Al battery systems, the usage of aqueous electrolyte is accompanied by the hydrogen evolution reaction as the standard reduction potential of $\mathrm{Al}^{3+}$ $\left(-1.68 \mathrm{~V} v s\right.$. standard hydrogen electrode) is lower than that of $\mathrm{H}_{2} \mathrm{O}$, thus making it difficult for use in a closed system. ${ }^{22,23}$ In this respect, the non-aqueous $\mathrm{Al}$ batteries with ionic liquid (IL) electrolytes with Al salts and organic moieties have emerged as important alternatives. ${ }^{24}$ These room temperature ionic liquids (RTILs) ${ }^{25}$ 
are used as potential electrolytes in secondary batteries owing to their wide electrochemical window, good thermal and chemical stability, low melting point, negligible volatility (thus low flammability) and high ionic conductivity. ${ }^{26}$ These are salts that exist in a liquid state below $100{ }^{\circ} \mathrm{C}$ and many are liquids at room temperature as a consequence of weak electrostatic interactions between cations and anions because of a greater number of alkyl groups present on the cation such that charge is prevented from transferring towards the anion. At present, various ionic liquid electrolytes have been explored and most of them have imidazolium cation moieties, ${ }^{27,28}$ whereas a few are pyrrolidinium ${ }^{29}$ or pyridinium-based ionic liquids. And among these electrolytes, imidazolium organic moieties are more favored as they offer a higher voltage and conductivity (due to their lower viscosity at room temperature). As a result, the $\mathrm{AlCl}_{3}$ :EMIM-Cl (1-ethyl-3-methylimidazolium chloride) ionic liquid has become the most widely used electrolyte in aluminium batteries, where Al can be reversibly stripped and deposited with $>90 \%$ coulombic efficiency, without any dendrite formation. ${ }^{30-33}$ However, the research on rechargeable Al DIBs with the RTIL electrolyte is in the primary stage and most of the published reports are experimental, which provide promising results, but further understanding is required to choose better ionic liquid electrolytes on the basis of their electrochemical window, relative interaction of electrolytes with the corresponding cathodes and anodes, and interatomic characteristics such as conductivity. In a recent study by Peljo et al., it was observed that the electrochemical window of electrolytes is not dependent upon their highest occupied molecular orbital (HOMO) or lowest unoccupied molecular orbital (LUMO) energy positions, but it is more related to the potential of electrolyte reduction at negative potentials, and the potential of electrolyte oxidation at positive potentials. However, they explored very limited systems including the water oxidation/reduction and $\mathrm{Fe}(\mathrm{III}) / \mathrm{Fe}$ (II) couple in aqueous solution ${ }^{34}$ and the results cannot be generalized for each system at present. For IL electrolyte systems, one similar study has been conducted by Wang et al., where the electrochemical window (ECW) was calculated for three different halogenated imidazolium salts, 1-butyl-3-methyl imidazolium halide (BMIM-X) $\left(\mathrm{X}=\mathrm{Cl}, \mathrm{Br}\right.$, and I) with $\mathrm{AlCl}_{3}$ systems. ${ }^{35}$ They observed that the ECW of the IL electrolyte decreases as anion size increases from $\mathrm{AlCl}_{4} \rightarrow \mathrm{AlCl}_{3} \mathrm{Br} \rightarrow \mathrm{AlCl}_{3} \mathrm{I}$, with a maximum value of $4.7 \mathrm{~V}$ obtained for $\mathrm{BMIM}-\mathrm{Cl} / \mathrm{AlCl}_{3}$. However, this study is also limited to the variation of the anions and does not consider the effect of cation selection. Therefore, it has further become necessary to investigate this concept of electrochemical stability for cation variation as well. As discussed earlier, various IL electrolytes have already been reported experimentally for Al DIBs and other metal ion batteries, but a more systematic approach is required to choose among these ILs to get a higher conductivity and high voltage for overall improved battery performance.

Therefore, in this work, we have carried out a systematic study to identify the potential ionic liquid electrolytes for $\mathrm{Al}$ DIBs using first principles calculations. We have considered a series of imidazolium organic moiety-based RTILs, such as 1-alkyl-3-methyl imidazolium chloride $\left(\mathrm{C}_{n}\right.$ mim-Cl, where $n=2$, $3,4,6$, and 8) with $\mathrm{AlCl}_{3}$ salts along with other molten saltbased electrolytes, such as, urea/ $\mathrm{AlCl}_{3}$ and acetamide/ $/ \mathrm{AlCl}_{3}$. The suitability is explored based on the ECW of the IL electrolytes with respect to their individual HOMO-LUMO energy levels. Moreover, the corresponding ionic conductivity and voltage calculations are also included to choose the efficient IL electrolytes for Al DIBs.

\section{Computational details}

First principles calculations are performed using the projected augmented wave (PAW) method as implemented in the Vienna $a b$ initio simulation package (VASP) for calculating the ion core and valence electron interaction. ${ }^{36-38}$ The exchange-correlation potential is described by using the generalized gradient approximation of Perdew-Burke-Ernzerhof (GGA-PBE). ${ }^{39}$ An energy cutoff of $470 \mathrm{eV}$ is used for the plane waves. All the optimized structures are obtained by fully relaxing both the atomic and lattice positions until the Hellmann-Feynman forces of all the atoms are smaller than $0.01 \mathrm{eV} \AA^{-1}$. The Brilliouin zone is chosen with a Gamma centered $k$-point grid of $21 \times 21 \times 7$ for the unit cell and $3 \times 3 \times 1$ for supercell calculations. All the systems are fully converged for the total energy set at $10^{-5} \mathrm{eV}$. The van der Waals interactions play a crucial role in layered systems and in individual ionic liquids; therefore, we have used the DFT-D3 approach for correction of the van der Waals interactions, which adds the vdW correction for the potential energy and interaction forces. ${ }^{40}$ Our optimized interlayer spacing of graphite $(3.34 \AA)$ is in close accordance with the experimentally reported value $(3.33 \AA) .{ }^{41}$

For the calculations of the HOMO and LUMO energies of the solvation model system, the SMD solvation model ${ }^{42}$ has been used for geometry optimization for all ILs (dielectric constant 12) using the B3LYP/6-31++G(d,p $)^{43,44}$ level of theory as implemented in Gaussian 09. ${ }^{45}$

\section{Results and discussion}

\subsection{Consideration of various $\mathrm{AlCl}_{3}$-based $\mathrm{IL}$ electrolytes}

The IL electrolytes examined in our study to understand the ECW and electrochemical properties are categorized into two groups: (i) RTILs having identical active imidazolium cation units with a variation in substituents, and (ii) molten ILs with different active cation ring moieties. These considered systems are represented in Fig. 1. The first category deals with the substituent effect on imidazolium-based ILs, where we vary the alkyl group of the imidazolium ring. This substituent effect by virtue of the steric hindrance could change the intermolecular forces between the imidazolium cation and chloroaluminate anion $\left(\mathrm{AlCl}_{4}{ }^{-}\right)$. This can also lead to a variation in the physical and chemical properties, such as conductivity, electrodeposition/ stripping of $\mathrm{Al}^{3+}$ at the anode, voltage variation and the reversibility of $\mathrm{AlCl}_{4}{ }^{-}$intercalation/deintercalation, and thus influences the overall capability of the electrolyte. In this category, we have 

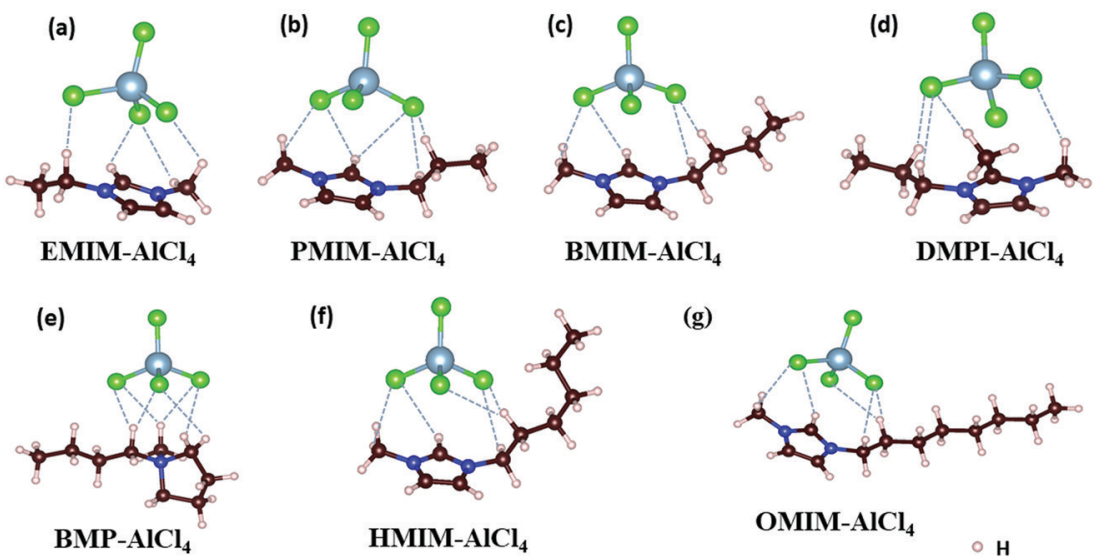

(f)

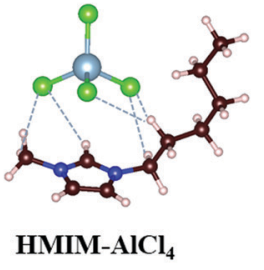

(g)

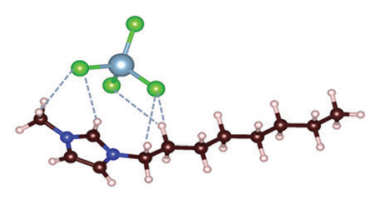

(h)
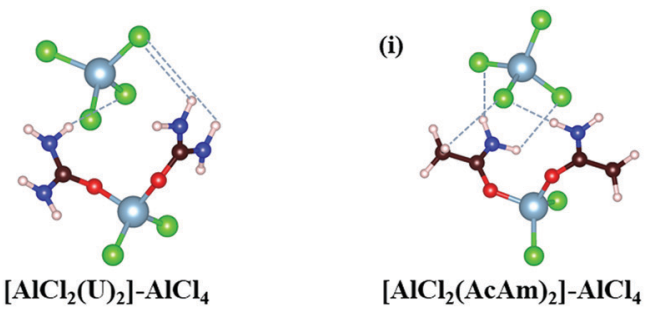

OMIM-AICl

$\circ \mathrm{H}$

- $N$

- $O$

- c

Cl

al

$\left[\mathrm{AlCl}_{\mathbf{2}}(\mathbf{A c A m})_{2}\right]-\mathrm{AlCl}_{\mathbf{4}}$

H-bonding (2.5-2.9 §)

Fig. 1 Optimized structures of the considered ionic liquid (a-g) and molten salt (h and i) electrolytes: (a) EMIM-AICl 4 , (b) PMIM-AICl 4 , (c) BMIM-AICl 4 , (d) $\mathrm{DMPI}-\mathrm{AlCl}_{4}$, (e) BMP-AlCl 4 , (f) $\mathrm{HMIM}-\mathrm{AlCl}_{4}$, (g) $\mathrm{OMIM}-\mathrm{AlCl}_{4}$, (h) $\left[\mathrm{AlCl}_{2}(\mathrm{U})_{2}\right]-\mathrm{AlCl}_{4}$, and (i) $\left[\mathrm{AlCl}_{2}\left(\mathrm{AcAm}_{2}\right]-\mathrm{AlCl}_{4}\right.$.

studied seven ionic liquid electrolyte systems, 1-ethyl-3-methyl imidazolium chloride ([EMIM]Cl), 1-propyl-3-methyl imidazolium chloride ([PMIM]Cl), 1-butyl-3-methyl imidazolium chloride ([BMIM]Cl), 1,2-dimethyl-3-propyl imidazolium chloride ([DMPI]Cl), 1-hexyl-3-methyl imidazolium chloride ([HMIM $] \mathrm{Cl})$, and 1-methyl-3octyl imidazolium chloride ([OMIM]Cl) with $\mathrm{AlCl}_{3}$, along with $N$-butyl- $N$-methyl pyrrolidinium chloride ([BMP]Cl). The second category of ionic liquids involves two molten salts, urea (U) and acetamide (AcAm) with $\mathrm{AlCl}_{3}$, where the most stable isomerase structures $\left(\left[\mathrm{AlCl}_{2}(\mathrm{U})_{2}\right] / \mathrm{AlCl}_{4}\right)$ and $\left(\left[\mathrm{AlCl}_{2}(\mathrm{AcAm})_{2}\right] / \mathrm{AlCl}_{4}\right)$ are considered. ${ }^{46}$ For each IL electrolyte system, we have examined at least four thermodynamically accessible configurations (Fig. S1, ESI $\dagger$ ), and the thus obtained most stable orientations (Fig. 1) are considered for further study. The most stable orientations have $\mathrm{Cl}$ atoms forming the maximum number of H-bonding interaction (within 2.5-2.9 A bond distances) with the nearest methylene hydrogens and $\mathrm{N}-\mathrm{H}$ containing hydrogens in imidazolium salts and molten salts, respectively. ${ }^{47,48}$

3.1.1. Evaluation of electrochemical window (ECW). The electrochemical window is one of the most important criteria to evaluate the electrochemical properties in electrolyte systems. It is defined as the difference between the cathodic and anodic limiting potentials, which are the potentials at which the respective cathodic reduction and anodic oxidation of electrolytes happen. The strong correlation of electrochemical potential with the energy of frontier orbitals defines the great importance of the electrochemical potentials for characterization of electronic properties of molecular species. The most predictable assumption is that the cathodic limiting potential $\left(V_{\mathrm{CL}}\right)$ is set by the LUMO and the anodic limiting potential $\left(V_{\mathrm{AL}}\right)$ is set by the HOMO. For the stable working of an electrolyte in batteries, the LUMO energy level must be positioned above the anode Fermi energy level $\left(\mu_{\mathrm{A}}\right)$ and the HOMO energy level must be positioned below the cathode Fermi energy $\left(\mu_{\mathrm{C}}\right)$ level of the electrochemical window of electrolytes, as shown in Fig. 2a. The open-circuit voltage $\left(V_{\mathrm{OC}}\right)$ of a cell is defined as the difference between the two Fermi energy potentials, $\mu_{\mathrm{A}}$ and $\mu_{\mathrm{C}}$, of the anode and cathode as: $V_{\mathrm{OC}}=\frac{\left(\mu_{\mathrm{A}}-\mu_{\mathrm{C}}\right)}{n e} \leq E_{\mathrm{g}}$, where $e$ is the electronic charge, $n$ is the number of electrons being transferred and $E_{\mathrm{g}}$ is the gap between the HOMO and LUMO. If in an electrolyte system, $\mu_{\mathrm{A}}$ is located above the LUMO, then the electrolyte undergoes reduction to form a solid electrolyte interface (SEI), which on excessive formation can block further anode electrolyte reaction; similarly, if the position of $\mu_{\mathrm{C}}$ is located below the HOMO, then the electrolyte is oxidized with the formation of the SEI, which will blocked further cathodic reaction. ${ }^{49}$ Therefore, the thermodynamic stability of the electrolyte requires location of the electrode electrochemical potentials $\mu_{\mathrm{C}}$ and $\mu_{\mathrm{A}}$ within the HOMO and LUMO of the electrolyte. This is the fundamental criterion of an electrolyte to form a stable battery system. However, at present, there is some misconception between the positions of the energy gap (HOMO and LUMO) and ECW of an electrolyte, as shown in Fig. $2 \mathrm{~b} .{ }^{34}$ There is no exact relation between the energy gap (HOMO and LUMO) and ECW, and the actual position of the ECW is observed to lie in the HOMOLUMO energy gap, however not necessarily at the exact position of the HOMO and LUMO values, as shown in Fig. 2c.

In our study, we have also tried to understand the abovediscussed relation between the HOMO-LUMO energy gap and ECW for the considered IL electrolytes to determine suitable electrolyte systems for more efficient Al DIBs. In order to 
(a)

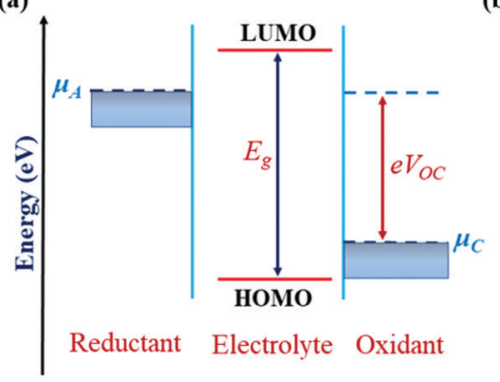

(b)

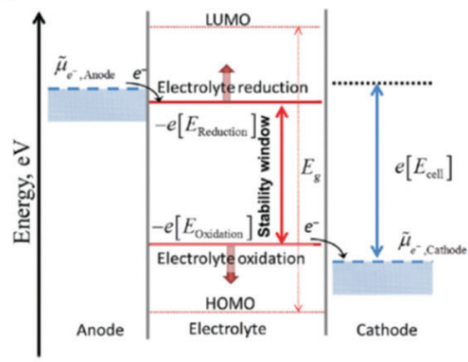

(c)

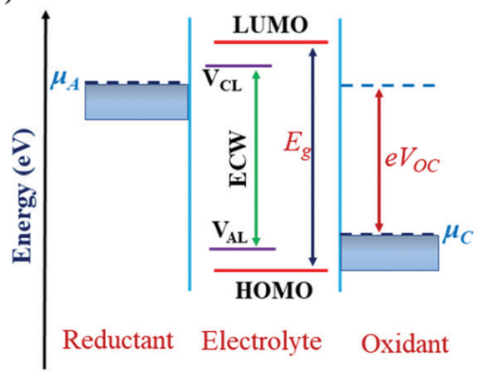

Fig. 2 Schematic diagrams of electrode position with respect to the corresponding HOMO-LUMO energy levels of electrolyte where: (a) both electrode Fermi energies $\left(\mu_{\mathrm{A}} \& \mu_{\mathrm{C}}\right.$ ) are placed within the HOMO-LUMO gap, and (b) correct notation for the negative and positive potential limits for the electrolyte stability, and the energy levels of the HOMO and LUMO. ${ }^{34}$ Reproduced from Ref. 34 with permission from Royal Society of Chemistry, Copyright 2018. (c) Stable energy profile of the electrochemical system, where cathodic limiting potential $\left(V_{C L}\right)$ is situated above the anode Fermi energy level and anodic limiting potential $\left(V_{\mathrm{AL}}\right)$ situated below the cathode Fermi energy level to avoid the unwanted oxidation and reduction of the electrolyte.

understand the underlying mechanism, we have considered the experimentally reported work functions of both the graphite cathode and $\mathrm{Al}$ anode in a vacuum medium. ${ }^{50,51}$ In this regard, we can define the standard redox potential on the absolute vacuum scale (AVS) by considering the virtual redox reaction between an oxidized species in solution (S) and an electron at rest in a vacuum (V): $\mathrm{Ox}^{\mathrm{S}}+\mathrm{e}^{-, \mathrm{V}} \leftrightarrow \operatorname{Red}^{\mathrm{S}}$. In an absolute vacuum, the scale standard hydrogen potential $E_{\frac{1}{2} \mathrm{H}^{+} / \mathrm{H}_{2}}$ is $4.44 \mathrm{~V}$ instead of $0.0 \mathrm{~V} .{ }^{52}$ So, now we can express the limiting $\mathrm{Al} / \mathrm{Al}^{3+}$ potential values (Table S1, ESI $\dagger$ ) of all the ionic liquids in terms of the absolute vacuum scale at $\mathrm{pH}=7$. This approach has also been successful in understanding the molecular level arrangement of the HOMO-LUMO positions of the electrolyte with respect to the Fermi positions of respective electrodes. ${ }^{34}$ Hence, we have studied the considered electrolytes in a schematic way (Fig. 3), where we have considered the two simultaneous potential scales, one being the absolute vacuum scale energy $(\mathrm{eV})$ and the other being the standard hydrogen electrode (SHE) for different types of electrolytes.

For the case of the EMIM-AlCl ${ }_{4}$ electrolyte, as shown in Fig. 3a, both cathodic $\left(V_{\mathrm{CL}}\right)$ and anodic $\left(V_{\mathrm{AL}}\right)$ limiting potentials are situated between the HOMO $(-7.42 \mathrm{eV})$ and LUMO $(-0.76 \mathrm{eV})$ of the electrolyte along with the electrode work functions of the cathode $\left(\mu_{\mathrm{C}}=-4.75 \mathrm{eV}\right)^{50}$ and anode $\left(\mu_{\mathrm{A}}=-4.17 \mathrm{eV}\right)^{51}$ thus it behaves as a stable system, as shown in Fig. 2c. According to this energy profile, if the anodic limiting potential $\left(V_{\mathrm{AL}}\right)$ is more than $2.34 \mathrm{~V}$ vs. $\left(\mathrm{Al} / \mathrm{Al}^{3+}\right), \mathrm{AlCl}_{4}{ }^{-}$undergoes oxidation to $\mathrm{Cl}_{2}$ gas $\left(4 \mathrm{AlCl}_{4}{ }^{-}-2 \mathrm{e} \rightarrow \mathrm{Cl}_{2}+2 \mathrm{Al}_{2} \mathrm{Cl}_{7}{ }^{-}\right),{ }^{35}$ and similarly, $\mathrm{EMIM}^{+}$would undergo reduction $\left(\mathrm{EMIM}^{+}+\mathrm{e} \rightarrow \mathrm{EMIM}\right)^{53}$ if the cathodic limiting potential $\left(V_{\mathrm{CL}}\right)$ is more than $-2.0 \mathrm{~V} v s$. $\left(\mathrm{Al} / \mathrm{Al}^{3+}\right)$. This results in the breakdown of reversibility of conversion reactions in Al DIBs. A similar explanation is also applicable for all

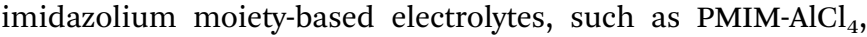

(a)

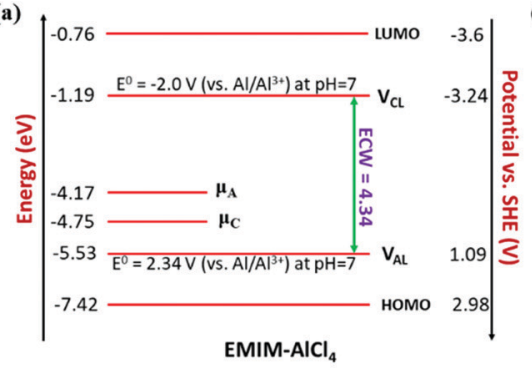

(b)

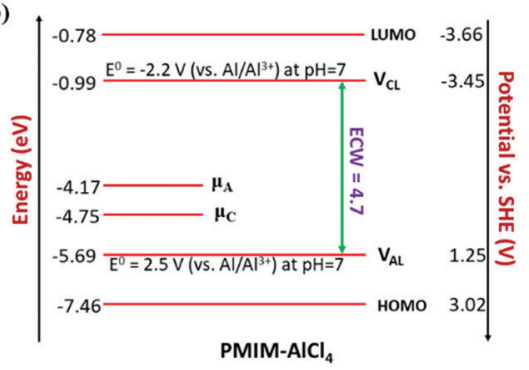

(c)

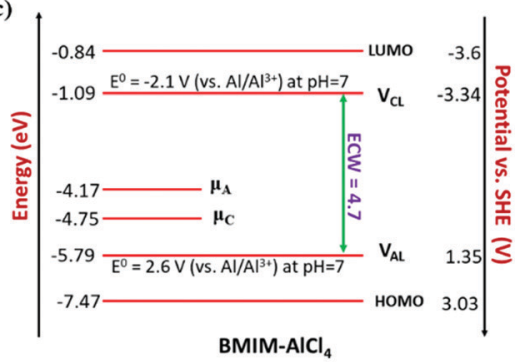

(d)

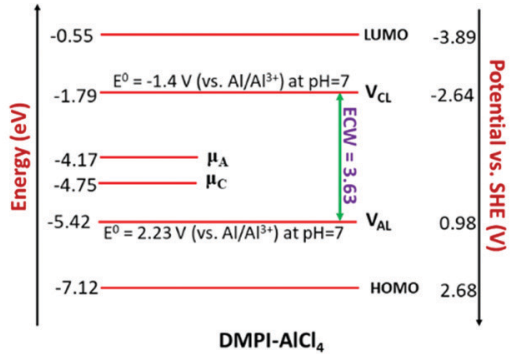

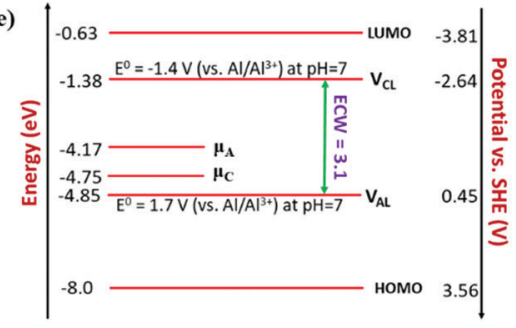

Urea-AICl

Fig. 3 Schematic diagram of ECW and the HOMO-LUMO energy positions of stable electrolyte systems with respect to electrode work function for

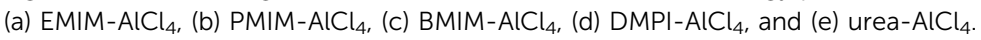


BMIM-AlCl $_{4}$ and DMPI-AlCl 4 (Fig. 3b-d), varying with different ECW values of $4.7 \mathrm{~V}, 4.7 \mathrm{~V}$ and $3.63 \mathrm{~V}$, respectively, which are experimentally verified by the reported results. ${ }^{35,54,55}$ These observations explain why the imidazolium IL electrolytes behave as stable electrolytes and, particularly, why $\mathrm{EMIM-AlCl}{ }_{4}$ with a broad electrochemical window $(4.34 \mathrm{~V})$ is the most preferred electrolyte in $\mathrm{Al}$ ion batteries. ${ }^{14-16,56}$ The ECW is not discussed for $\mathrm{HMIM}-\mathrm{AlCl}_{4}$ and $\mathrm{OMIM}-\mathrm{AlCl}_{4}$ electrolytes due to the nonavailabilty of their experimental oxidation and reduction limiting potential values. The reduction of urea- $\mathrm{AlCl}_{4}$ is a little different due to the existence of isomeric cationic species $\left[\mathrm{AlCl}_{2}(\mathrm{U})_{2}\right]^{+}$with $\mathrm{AlCl}_{4}{ }^{-}$. It involves a relatively lower energy barrier $(0.1 \mathrm{eV})$ of electron transfer from the oxidation limiting $\left(V_{\mathrm{AL}}\right)$ potential to the cathode, making urea- $\mathrm{AlCl}_{4}$ susceptible to oxidation along with having a narrow electrochemical window (3.1 V) compared to the imidazolium-based ionic liquid electrolytes (3.6-4.7 V). However, the higher availability and low cost of urea still make the urea- $\mathrm{AlCl}_{4}$ electrolyte a fairly suitable option in Al DIBs.

We observe an altogether different behaviour of the ECW for BMP-AlCl ${ }_{4}$ and the molten salt AcAm-AlCl${ }_{4}$, as shown in Fig. 4. For both systems, $V_{\mathrm{CL}}$ and $V_{\mathrm{AL}}$ are found to be placed above the work functions of the cathode and anode in their respective electrochemical window. This can lead to both oxidation of $\mathrm{AlCl}_{4}{ }^{-}$and reduction of the BMP/AcAm cation in a simultaneous way, which could lead to the formation of a SEI layer, restricting the battery efficiency. As a result, the concentration of ionic salt is not maintained constantly throughout the reaction, leading to a breakdown of the overall reversibility of the electrolyte in the system. The reason behind both the reduction and oxidation can be explained by the charge analysis of the $\mathrm{BMP}^{+}$ring and $\mathrm{AlCl}_{4}{ }^{-}$. The stability of imidazolium ringbased systems can be correlated with the delocalization of charge through the cation ring. Moreover, based on natural bond orbital (NBO) charge analysis, ${ }^{57}$ we have observed that two of the nitrogen atoms of $\mathrm{EMIM}^{+}$have higher charges $(-0.353|e|$ and $-0.350|e|)$ compared to the charge on the single nitrogen atom $(-0.346|e|)$ in the BMP ring (Fig. S2, ESI $\dagger$ ). This indicates a stronger interaction between cation and anion in the $\mathrm{EMIM-AlCl}{ }_{4}$ system

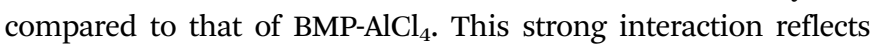
the less tendency of the respective cations and anions to undergo reduction and oxidation in the $\mathrm{EMIM-AlCl}{ }_{4}$ electrolyte compared to the $\mathrm{BMP}-\mathrm{AlCl}_{4}$ electrolyte. Overall, the $\mathrm{BMP}-\mathrm{AlCl}_{4}$ electrolyte is an unsuitable electrolyte in the $\mathrm{Al}$ ion battery on the basis of both stability and window potential $(0.25 \mathrm{~V})$. However, experimentally, the electrochemical properties of the $\mathrm{AcAm}-\mathrm{AlCl}_{4}$ system are found to improve as a result of a solvent effect by dichloromethane (DCM) addition. ${ }^{58}$ The solvation effect is shown to drastically change the properties such as stability and potential window and discharge capacity due to the dilution of the electrolyte. Overall, from the electrochemical window study, we can confirm that the EMIM-AlCl ${ }_{4}, \mathrm{PMIM}^{-}$ $\mathrm{AlCl}_{4}, \mathrm{BMIM}-\mathrm{AlCl}_{4}, \mathrm{DMPI}-\mathrm{AlCl}_{4}$ and urea-AlCl${ }_{4}$ electrolytes are more suitable for Al DIBs compared to the $\mathrm{BMP}^{-\mathrm{AlCl}_{4}}$ and AcAm-AlCl${ }_{4}$ electrolytes. This potential window concept can be helpful in designing stable electrolytes with wide electrochemical windows for Al DIBs.

3.1.2. Ionic conductivity of ionic liquid electrolytes. Ionic conductivity of an electrolyte plays an important role in determining its suitability in battery application. It depends upon the mobility of the electrolyte, i.e. how fast the ions can move inside the electrolyte, which is further related to the electrostatic interactions between the involved ions of the electrolyte. Using an electrolyte with higher ionic conductivity improves the rate performance of the battery by directly influencing the charge/discharge processes. Therefore, along with the electrochemical window, the suitability of the involved IL electrolytes can also be determined by calculating their respective ionic conductivities. In our study, we have used the revised form of the Stokes-Einstein equation of ionic conductivity, $\kappa=\frac{Z^{2} F e \rho}{6 \pi \eta M_{\mathrm{w}}}\left({R_{+}}^{-1}+R_{-}{ }^{-1}\right)$, proposed by Abbott et al. ${ }^{59}$ to calculate the ionic conductivities. The detailed derivation of this revised expression of the Stokes-Einstein equation can be understood as follows along with the discussion of important approximations/limitations:

The conductivity of a liquid salt can be described as ${ }^{60}$

$$
\kappa=F\left(C_{+}{ }^{\prime} u_{+}+C_{-}{ }^{\prime} u_{-}\right)
$$

where $C_{+}{ }^{\prime}=C_{-}{ }^{\prime}=y C$, and $C_{+}{ }^{\prime} / u_{+}$and $C_{-}{ }^{\prime} / u_{-}$are the concentration/mobility of the cation and anion, respectively.
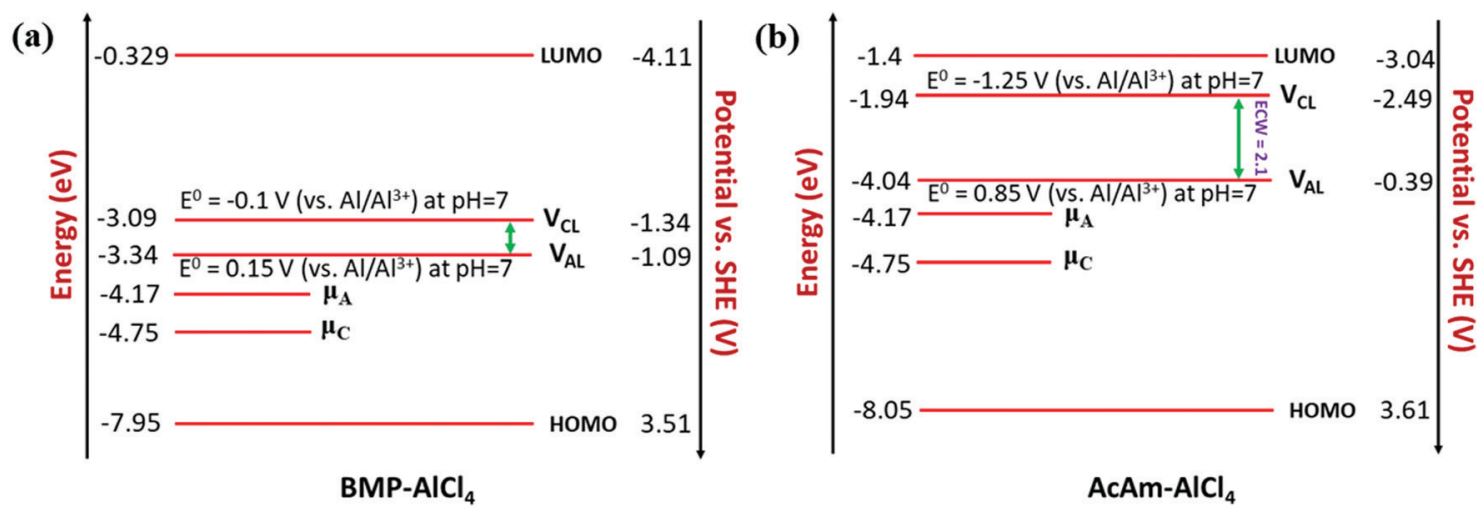

Fig. 4 Schematic diagram of ECW and HOMO-LUMO energy position with respect to electrode work function of the unstable electrolytes (a) BMP$\mathrm{AlCl}_{4}$ and (b) $\mathrm{AcAm}_{-} \mathrm{AlCl}_{4}$. 
Therefore,

$$
\kappa=y F C\left(u_{+}+u_{-}\right)
$$

Eqn (2) represents a modified form of the Stokes-Einstein relation. Here, $y$ represents the degree of dissociation varying between 0 and 1 . The approximation associated with eqn (2) was noted in a previous study by Harris et al. ${ }^{61}$ and it assumes that the IL behaves as an infinitely diluted solution. This approximation does not consider the ion-solvent interactions and assumes that the ion-ion interactions are limited to the association to form neutral species.

A more accurate modified form of the Stokes-Einstein relation correlates ionic transport to viscosity of the medium,

$$
D_{+}=\frac{R T}{6 \pi N_{\mathrm{A}} \eta \xi_{+} R_{+}} \text {and } D_{-}=\frac{R T}{6 \pi N_{\mathrm{A}} \eta \xi_{-} R_{-}},
$$

where $D_{+}$and $D_{-}$are the diffusivity constants of the cation and anion, respectively, and $\eta$ is the viscosity (Table S2, ESI $\dagger$ ). $N_{\mathrm{A}}$ is the Avogadro constant, and $\xi_{+}$and $\xi_{-}$are the correction factors obtained by taking into account the specific interaction between the cations and anions in a salt with $R_{+}$and $R_{-}$ionic radii, respectively.

Further,

$$
u_{+}=D_{+} F / R T \text { and } u_{-}=D_{-} F / R T
$$

Combining eqn (2)-(4) derives a form of the Stokes-Einstein equation as obtained by Bonhôte et al., ${ }^{60}$ which expresses the specific conductivity of charge in an ambient temperature IL as follows,

$$
\kappa=\frac{y F^{2} \rho}{6 \pi N_{\mathrm{A}} M_{\mathrm{w}} \eta}\left[\left(\xi_{+} R_{+}\right)^{-1}+\left(\xi_{-} R_{-}\right)^{-1}\right]
$$

where $y$ is the degree of dissociation, $F$ is the Faraday constant, $\rho$ is the density and $M_{\mathrm{w}}$ is the molar mass of the IL. This conductivity equation is observed to be in qualitative agreement with the measured data, but because the values of $y, \xi_{+}$ and $\xi_{-}$cannot be determined accurately, the accuracy of the theory could not be established.

Abbott et al. further derived the above-mentioned StokesEinstein eqn (5) by applying hole theory. ${ }^{59}$ Hole theory is applicable to both ionic and molecular fluids to account for viscosity, ${ }^{62}$ which is limited by the availability of the holes. Since the fraction of suitably sized holes in ambienttemperature ionic liquids is very low (about $10^{-6}$ ), the holes are assumed at infinite dilution. And as the migration of holes is independent of each other, they can be described by the Stokes-Einstein equation as

$$
\lambda_{+}=Z^{2} \mathrm{Fe} / 6 \pi \eta R_{+}
$$

where $Z$ is the charge on the ion and $e$ is the electronic charge. As the Stokes-Einstein equation is valid for both the ions, the molar conductivities of the ionic liquid can be written as,

$$
\Lambda=\lambda_{+}+\lambda_{-}
$$

Therefore, the net equation of conductivity can be written as eqn (8), which has been used in our study to determine the ionic conductivities of the ionic liquids.

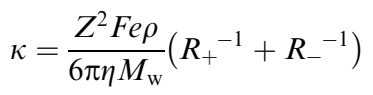

The corresponding ionic radii are obtained by calculating the volumes of spherical structures of both cation and anion and are in accordance with the experimental values (Table S3, ESI $\dagger$ ).

The above conductivity equation is basically derived for noninteracting ions, as in an infinitely diluted electrolyte solution. However, in reality, mass, charge, momentum, and energy transport processes in the ionic liquids and molten salts involve correlated interionic collisions, caging, and vortex motions. Therefore, the calculated conductivities cannot be expected to exactly match with the measured conductivities but do provide qualitative values. Here, we consider the molar ratio of $1: 1$ $\left(\mathrm{AlCl}_{3}\right.$ : salt) of the IL electrolyte. This is because for an IL ratio higher than $1: 1$, the deviation from the Stokes-Einstein equation is more prominent due to the stronger ion-solvent interactions, which are difficult to ignore. ${ }^{61}$

The calculated ionic conductivities for the IL electrolytes under investigation are plotted in Fig. 5.

We observe that for the case of the imidazolium cation moiety-based RTIL electrolytes, as the size of the alkyl chain $\left(R_{+}\right)$increases from ethyl (EMIM) to octyl (OMIM), the conductivity of the IL electrolyte gradually diminishes with a maximum conductivity of $14.1 \mathrm{mS} \mathrm{cm}^{-1}$ for EMIM-AlCl 4 , and this trend is in accordance with that of a previously reported study. ${ }^{63}$ From eqn (8), we can clearly observe that the resultant conductivity mainly varies with the density, viscosity, molecular weight and the ionic radii of the considered ionic salts. And, for the imidazolium cation-based room temperature IL electrolytes, the decrease of the conductivity with the alkyl chain length is the result of the decreasing density of the ionic liquids from ethyl (EMIM) to octyl (OMIM), while the opposite trend is observed for viscosity, because of the longer aliphatic chain resulting in increased viscosity. The variation in density can be correlated with the packing efficiency of the molecules, which decreases with the increase in the size of the alkyl substitution of the imidazolium ring and thus results in an overall decrease

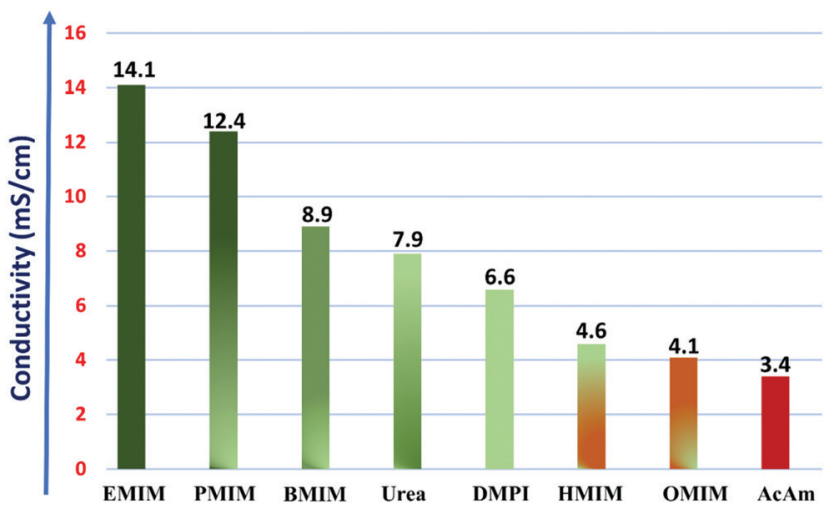

Fig. 5 Variation of ionic conductivity of the considered IL electrolytes. Here, the dark green and red colors represent the higher and lower ionic conductivity values, respectively. 
in ionic conductivity. On the other hand, the origin of the viscosity trend is likely to be more complex, as it is measured by the internal friction in the system, however a number of parameters contribute to it, such as molecular shape, size, molar mass, temperature and the forces between the ions. In this case, the increase in viscosity could be the resultant combination of the increase in the alkyl chain length, which can restrict their movement in electrolyte, and the increase in dispersion forces due to an overall increase of the molar volume of the electrolyte system. As a result, there is a gradual decrease in the ionic mobility of the ions and the overall ionic conductivity.

In the case of the $\mathrm{BMP}^{-\mathrm{AlCl}_{4}}$ electrolyte, due to the nonavailability of the physical terms such as density and viscosity, we could not calculate the conductivity, however its conductivity is expected to be much smaller (having a larger size) than that of the EMIM- $\mathrm{AlCl}_{4}$ system. ${ }^{64}$

However, for the case of the molten salt systems such as urea- $\mathrm{AlCl}_{4}\left(7.9 \mathrm{mS} \mathrm{cm}{ }^{-1}\right)$ and $\left.\mathrm{AcAm}^{-\mathrm{AlCl}_{4}(3.4 \mathrm{mS} \mathrm{cm}}{ }^{-1}\right)$, the observed conductivities are lower than those of the room temperature IL electrolytes, even though they operate at higher temperatures and generally have lower viscosities. In the case of both urea and AcAm, the larger cation size $\left(R_{+}\right)$and molecular electrochemical window, but also by actively participating in the net electrochemical reaction of charging and discharging. Therefore, the potential applicability of the IL electrolytes can also be concluded on the basis of the overall voltage. In the voltage calculation, we have considered the $\mathrm{AlCl}_{3} /$ cation for ionic liquid electrolytes with a molar ratio $>1$ : 1 to have extra $\mathrm{AlCl}_{3}$ for generation of the $\mathrm{Al}_{2} \mathrm{Cl}_{7}$ ion, which takes part in the charge/discharge reaction mechanism.

The reaction mechanism of Al DIBs involves the intercalation/ deintercalation of $\mathrm{AlCl}_{4}{ }^{-}$at the cathode and electrodeposition/ stripping of $\mathrm{Al}$ metal at the anode during the charge/ discharge process. The net charge/discharge reaction involving the conversion reactions between $\mathrm{AlCl}_{4}{ }^{-}$and $\mathrm{Al}_{2} \mathrm{Cl}_{7}{ }^{-}$is given below.

$$
\begin{aligned}
& \mathrm{Al}+7 \mathrm{AlCl}_{4}{ }^{-} \leftrightarrow 4 \mathrm{Al}_{2} \mathrm{Cl}_{7}{ }^{-}+3 \mathrm{e}^{-} \text {(anode) } \\
& \mathrm{C}_{n}\left[\mathrm{AlCl}_{4}\right]+\mathrm{e}^{-} \leftrightarrow \mathrm{C}_{n}+\mathrm{AlCl}_{4}{ }^{-} \text {(cathode) }
\end{aligned}
$$

For previously studied Al DIBs, the voltage eqn (11) was successfully observed to give quite accurate voltage values in accordance with the corresponding experimental voltage range. Therefore, for the comparative study of the IL electrolytes, we also used the following equation to calculate the voltage.

$$
V=\left[\frac{\left\{\frac{3}{x} E_{C_{n}}+4 E_{\left[(\text {cation })^{+} \mathrm{Al}_{2} \mathrm{Cl}_{7}^{-}\right]}\right\}-\left\{\frac{3}{x} E_{\left[\left(\mathrm{AlCl}_{4}\right)_{x} C_{n}\right]}+4 E_{\left[(\text {cation })+\mathrm{AlCl}_{4}^{-}\right]}+E_{\mathrm{Al}}\right\}}{z}\right]
$$

weight are the predominant factors, which reduce the overall conductivities compared to the contribution of the lower viscosity values at higher temperatures. The conductivity of the urea-AlCl${ }_{4}$ system is much higher than that of the AcAm- $\mathrm{AlCl}_{4}$ system due to the lower molecular weight, higher density and small cation size. Moreover, in a recent report, Michael Angell et al. have also shown that $\mathrm{AlCl}_{3}$ containing urea derivatives such as $\mathrm{N}$-methyl urea and its salts act as preferential electrolytes having higher ionic conductivities in Al-DIBs due to their lower viscosities. ${ }^{65}$

Overall, from the ionic conductivity calculations, we conclude that the RTIL electrolytes with smaller alkyl substituents and higher conductivity are superior choices for rechargeable battery electrolytes. Especially, the highest ionic conductivity of EMIM-AlCl ${ }_{4}$ could be one of the reasons for its selective choice in most of the experimental studies of Al DIBs. ${ }^{14-17,66}$ However, in a recent study of $\mathrm{Al}$ DIBs by Yang et al., it was observed that

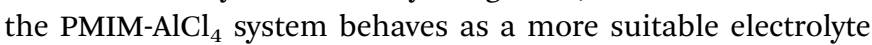
with $100 \%$ coulombic efficiency compared to the $\mathrm{EMIM}^{-\mathrm{AlCl}_{4}}$ (95\%) system. ${ }^{14,63}$ And, our study also shows that the ionic conductivity of the $\left.\mathrm{PMIM}^{-\mathrm{AlCl}_{4} \text { system is quite high }(12.4 \mathrm{mS} \mathrm{cm}}{ }^{-1}\right)$.

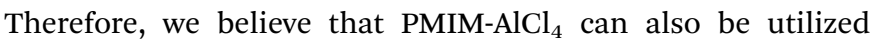
as a suitable next generation electrolyte instead of $\mathrm{EMIM}^{-\mathrm{AlCl}_{4}}$ in Al DIBs.

\subsection{Voltage characteristics}

Unlike the metal-ion batteries, the electrolyte in Al DIBs determines the voltage, not only in terms of deciding the where $E_{\left[\left(\mathrm{AlCl}_{4}\right)_{x} C_{n}\right]}, E_{\left[(\text {cation })^{+} \mathrm{AlCl}_{4}^{-}\right]}$and $E_{\left[(\text {cation })^{+} \mathrm{Al}_{2} \mathrm{Cl}_{7}^{-}\right]}$are the total energies of the $\mathrm{AlCl}_{4}{ }^{-}$intercalated graphite system, (cation) ${ }^{+} \mathrm{AlCl}_{4}{ }^{-}$and (cation) ${ }^{+} \mathrm{Al}_{2} \mathrm{Cl}_{7}{ }^{-}$, respectively. $E_{\mathrm{Al}}$ is the total energy of a single $\mathrm{Al}$ atom in a bulk fcc structure and $E_{C_{n}}$ is the total energy of the graphite system. The energies $E_{\left[(\text {cation })^{+} \mathrm{AlCl}_{4}{ }^{-}\right]}$ and $E_{\left[(\text {cation })^{+} \mathrm{Al}_{2} \mathrm{Cl}_{7}{ }^{-}\right]}$are calculated by optimizing (cation) ${ }^{+} \mathrm{AlCl}_{4}{ }^{-}$ and (cation) ${ }^{+} \mathrm{Al}_{2} \mathrm{Cl}_{7}{ }^{-}$as molecular species due to the nonavailability of their crystal structures. The optimized structures of the individual (cation) ${ }^{+} \mathrm{Al}_{2} \mathrm{Cl}_{7}^{-}$pairs along with their total energies are given in Fig. S3, ESI. $\dagger$

In this study, to compare the voltage of the considered IL electrolytes, we have studied a stage- $1 \mathrm{AlCl}_{4}{ }^{-}$intercalated graphite system with the $\mathrm{C}_{18}\left[\mathrm{AlCl}_{4}\right]$ formula unit, ${ }^{68}$ constructed using a $3 \times 3 \times 1$ supercell of graphite. We observe that for the imidazolium-based IL electrolytes, the voltage does not vary in a monotonic fashion when increasing the alkyl chain length, as shown in Table 1, where the highest voltage of $2.46 \mathrm{~V}$ is

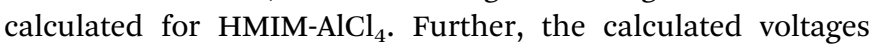

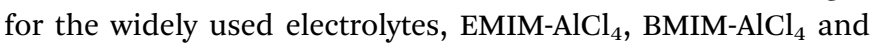
$\mathrm{DMPI}^{-\mathrm{AlCl}_{4}}$, for $\mathrm{Al}$ dual-ion batteries are $2.25 \mathrm{~V}, 2.40 \mathrm{~V}$ and $2.24 \mathrm{~V}$, respectively, which are also in close accordance with the experimentally reported voltage ranges of 2.25-2.0 V, 2.3-1.98 V and $2.0-1.7 \mathrm{~V}$, respectively. ${ }^{14,55,67}$ On the other hand, the molten salt electrolytes, urea- $\mathrm{AlCl}_{4}$ and $\mathrm{AcAm-AlCl}{ }_{4}$, are also observed to have similar ranges to that of the RTIL electrolytes with the voltage values of $2.35 \mathrm{~V}$ and $2.21 \mathrm{~V}$, respectively, which closely resemble their experimentally reported values of 2.3-1.9 $\mathrm{V}$ and 2.3-2.0 V, respectively. ${ }^{58,65}$ 
Table 1 Calculated theoretical voltages for the considered IL electrolytes and their corresponding experimental values. Here, "-" corresponds to the non-availability of experimental values

\begin{tabular}{lll}
\hline Electrolyte & Calculated voltage (V) & Experimental voltage (V) \\
\hline EMIM-AlCl $_{4}$ & 2.25 & $2.25-2.0^{14,66}$ \\
PMIM-AlCl $_{4}$ & 2.28 & - \\
BMIM-AlCl $_{4}$ & 2.40 & $2.3-1.98^{67}$ \\
DMPI-AlCl $_{4}$ & 2.24 & $2.0-1.7^{55}$ \\
HMIM-AlCl $_{4}$ & 2.46 & - \\
OMIM-AlCl $_{4}$ & 2.35 & - \\
BMP-AlCl $_{4}$ & 2.40 & - \\
Urea-AlCl & 2.35 & $2.3-1.9^{65}$ \\
AcAm-AlCl & 2.21 & $2.3-2.0^{58}$
\end{tabular}

The voltage analysis shows that all the considered IL electrolytes provide similar voltages ranging from 2.21 to $2.46 \mathrm{~V}$ and the suitability of the electrolyte cannot be directly concluded from the voltage alone as other factors such as conductivity and electrochemical stability also have an equal deciding role. For example, even though $\mathrm{HMIM}-\mathrm{AlCl}_{4}$ has a high voltage value of $2.46 \mathrm{~V}$, it cannot be used as a preferential electrolyte in Al DIBs as its ionic conductivity value $\left(4.6 \mathrm{mS} \mathrm{cm}^{-1}\right)$ is very low.

Based on all three properties, electrochemical window, conductivity and voltage analyzed in this report, we can conclude that EMIM-AlCl 4 , PMIM-AlCl 4 , BMIM-AlCl ${ }_{4}, \mathrm{DMPI}-\mathrm{AlCl}_{4}$ and urea-AlCl${ }_{4}$ have desirable characteristics for use as an electrolyte in Al DIBs possessing a suitably large electrochemical window $(4.38 \mathrm{~V}, 4.7 \mathrm{~V}$, $4.7 \mathrm{~V}, 3.63 \mathrm{~V}$, and $3.1 \mathrm{~V}$ ) and high conductivities (14.1, 12.4, 8.9, 6.6, and $\left.7.9 \mathrm{mS} \mathrm{cm}^{-1}\right)$ as well as reasonably high voltages $(2.25 \mathrm{~V}, 2.38 \mathrm{~V}$, $2.40 \mathrm{~V}, 2.24 \mathrm{~V}$, and $2.35 \mathrm{~V}$ ), respectively. Our study also provides a reason for the preferential use of the $\mathrm{EMIM}-\mathrm{AlCl}_{4}$ electrolyte in various experimental Al DIBs. Moreover, another important IL electrolyte, which can be further used in Al DIBs, is PMIM-AlCl 4 , which offers a sufficiently high voltage $(2.38 \mathrm{~V})$, electrochemical window $(4.7 \mathrm{~V})$ and reasonably high conductivity $\left(12.4 \mathrm{mS} \mathrm{cm}^{-1}\right)$ like

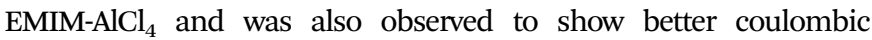
efficiency than EMIM-AlCl ${ }_{4}$ in a recent experimental report. ${ }^{63}$

\section{Conclusion and outlook}

In conclusion, we have systematically identified suitable ionic liquid and molten salt electrolytes for $\mathrm{Al}$ dual-ion batteries (DIBs) by analyzing the characteristics, such as electrochemical window, ionic conductivities and voltages. Here, we study a series of imidazolium-based $\mathrm{AlCl}_{3}$ salt electrolytes by varying the alkyl substituent in the imidazolium ring cation and molten salt electrolytes, such as urea/ $\mathrm{AlCl}_{3}$, and acetamide/ $\mathrm{AlCl}_{3}$. We initiated the study by analyzing the misconception of the relation between the HOMO-LUMO energy gap and the electrochemical window (ECW) of electrolytes, which states that the ECW values are not the same as the energy positions of the HOMO-LUMO, but in actuality they reside inside the HOMOLUMO gap. In our considered systems, the imidazolium

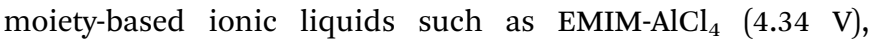

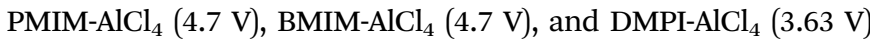
are observed to have high ECW values indicating their higher stability towards both cation reduction and anion oxidation. On the other hand, the pyrrolidinium moiety-based $\mathrm{BMP}-\mathrm{AlCl}_{4}$ furnishes a small ECW $(0.25 \mathrm{~V})$ and is more susceptible to both oxidation of $\mathrm{AlCl}_{4}{ }^{-}$and reduction of $\mathrm{BMP}^{+}$, which could obstruct further reaction on the electrode through SEI formation. In the case of the molten salt electrolytes, urea- $\mathrm{AlCl}_{4}$ can be considered as a suitable electrolyte for Al DIBs with a broad ECW (3.1 V) compared to a smaller ECW (2.1 V) of the AcAm-AlCl 4 electrolyte. The second characteristic, the ionic conductivity, which is governed by factors such as viscosity, temperature and cation-anion size of the IL electrolyte, also shows varying values for the considered IL electrolytes. In the case of the imidazolium-based ionic liquids, the ionic conductivity decreases from $\mathrm{EMIM-AlCl} 4$ $\left(14.1 \mathrm{mS} \mathrm{cm}{ }^{-1}\right)$ to $\mathrm{OMIM}^{-\mathrm{AlCl}_{4}}\left(4.1 \mathrm{mS} \mathrm{cm}^{-1}\right)$ with the increase in the alkyl chain length of the cation due to an abrupt increase of the cation size, which is in good agreement with a previous report. ${ }^{63}$ We observe that the ionic conductivity also favors the urea-AlCl ${ }_{4}$ molten salt with higher conductivity $\left(7.9 \mathrm{mS} \mathrm{cm}{ }^{-1}\right)$ compared to $\mathrm{AcAm}^{-\mathrm{AlCl}_{4}}\left(3.4 \mathrm{mS} \mathrm{cm}{ }^{-1}\right)$ as a result of the higher density and lower molecular weight and lower cationic size of the urea $^{+}$ion. The third characteristic is the average voltage, which is observed to show very similar output values for all the studied IL electrolytes within the range of 2.4-2.2 V, showing good agreement with the experimentally reported voltages (2.3-1.7 V). Our results clearly explain the preferential usage of $\mathrm{EMIM}-\mathrm{AlCl}_{4}$ in $\mathrm{Al}$ DIB technology as it furnishes a large ECW, higher conductivity and increased voltage. Other than that, we believe that PMIM$\mathrm{AlCl}_{4}$ could also be a preferable choice as it not only shows a higher ECW value (4.7 V) and high ionic conductivity $\left(12.4 \mathrm{mS} \mathrm{cm}^{-1}\right)$ but also provides a higher coulombic efficiency compared to that of EMIM-AlCl${ }_{4}$ as observed in a recent experimental study. ${ }^{56}$ Additionally, the molten salt (specially the urea containing salt) ionic liquid could also be useful in Al DIBs in terms of practical applications compared to the costly imidazolium-based ionic liquids. Overall, these results provide an in-depth understanding to design an efficient electrolyte with suitable electrochemical properties for Al DIBs.

\section{Conflicts of interest}

There are no conflicts to declare.

\section{Acknowledgements}

We thank IIT Indore for the lab and computing facilities. This work is supported by DST-SERB (Project Number CRG/2018/ 001131) and SPARC (Project Number SPARC/2018-2019/P116/ SL), New Delhi. S. S. M. thanks CSIR and P. B. thanks MHRD for research fellowships. We would like to thank Sandeep Das for his valuable suggestion.

\section{References}

1 S. Linic, P. Christopher and D. B. Ingram, Nat. Mater., 2011, 10, 911-921. 
2 Y. Zhou, P. Luckow, S. J. Smith and L. Clarke, Environ. Sci. Technol., 2012, 46, 7857-7864.

3 M. Kaltenbrunner, M. S. White, E. D. Glowacki, T. Sekitani, T. Someya, N. S. Sariciftci and S. Bauer, Nat. Commun., 2012, 3, 770 .

4 G. Dennler, M. C. Scharber and C. J. Brabec, Adv. Mater., 2009, 21, 1323-1338.

5 T. Ackermann and L. Soder, Renewable Sustainable Energy Rev., 2002, 6, 67-128.

6 J. Wen, Y. Yu and C. Chen, Mater. Express, 2012, 2, 197-212.

7 K. Liu, Y. Liu, D. Lin, A. Pei and Y. Cui, Sci. Adv., 2018, 4, eaas9820.

8 V. Palomares, P. Serras, I. Villaluenga, K. B. Hueso, J. Carretero-Gonzalez and T. Rojo, Energy Environ. Sci., 2012, 5, 5884-5901.

9 L. O. Vogt, C. Marino and C. Villevieille, Chimia, 2015, 69, 729-733.

10 J. Billaud, R. J. Clément, A. R. Armstrong, J. CanalesVázquez, P. Rozier, C. P. Grey and P. G. Bruce, J. Am. Chem. Soc., 2014, 136, 17243-17248.

11 G. Singh, N. Tapia-Ruiz, J. M. Lopez del Amo, U. Maitra, J. W. Somerville, A. R. Armstrong, J. Martinez de Ilarduya, T. Rojo and P. G. Bruce, Chem. Mater., 2016, 28, 5087-5094.

12 J. Muldoon, C. B. Bucur and T. Gregory, Chem. Rev., 2014, 114, 11683-11720.

13 B. Pan, J. Huang, Z. Feng, L. Zeng, M. He, L. Zhang, J. T. Vaughey, M. J. Bedzyk, P. Fenter, Z. Zhang, A. K. Burrell and C. Liao, Adv. Energy Mater., 2016, 6, 1600140.

14 M.-C. Lin, M. Gong, B. Lu, Y. Wu, D.-Y. Wang, M. Guan, M. Angell, C. Chen, J. Yang, B.-J. Hwang and H. Dai, Nature, 2015, 520, 324-328.

15 N. Jayaprakash, S. K. Das and L. A. Archer, Chem. Commun., 2011, 47, 12610-12612.

16 J. V. Rani, V. Kanakaiah, T. Dadmal, M. S. Rao and S. Bhavanarushi, J. Electrochem. Soc., 2013, 160, A1781-A1784.

17 S. C. Jung, Y.-J. Kang, D.-J. Yoo, J. W. Choi and Y.-K. Han, J. Phys. Chem. C, 2016, 120, 13384-13389.

18 Z. A. Zafar, S. Imtiaz, R. Razaq, S. Ji, T. Huang, Z. Zhang, Y. Huang and J. A. Anderson, J. Mater. Chem. A, 2017, 5, 5646.

19 L. Fu, N. Li, Y. Liu, W. Wang, Y. Zhu and Y. Wu, Chin. J. Chem., 2017, 35, 13-20.

20 G. A. Elia, K. Marquardt, K. Hoeppner, S. Fantini, R. Lin, E. Knipping, W. Peters, J.-F. Drillet, S. Passerini and R. Hahn, Adv. Mater., 2016, 28, 7564-7579.

21 Y. Wang, R. Chen, T. Chen, H. Lv, G. Zhu, L. Ma, C. Wang, Z. Jin and J. Liu, Energy Storage Mater., 2016, 4, 103-129.

22 S. Liu, J. J. Hu, N. F. Yan, G. L. Pan, G. R. Li and X. P. Gao, Energy Environ. Sci., 2012, 5, 9743-9746.

23 Y. J. He, J. F. Peng, W. Chu, Y. Z. Lia and D. G. Tong, J. Mater. Chem. A, 2014, 2, 1721-1731.

24 Q. Li and N. J. Bjerrum, J. Power Sources, 2002, 110, 1-10.

25 E. W. Castner and J. F. Wishart, J. Chem. Phys., 2010, 132, 120901.

26 H. Weingaertner, Angew. Chem., Int. Ed., 2008, 47, 654-670.

27 H. Srour, L. Chancelier, E. Bolimowska, T. Gute, S. Mailley, H. Rouault and C. C. Santini, J. Appl. Electrochem., 2016, 46, 149-155.
28 J.-K. Kima, A. Matic, J.-H. Ahnb and P. Jacobsson, J. Power Sources, 2010, 195, 7639-7643.

29 (a) G. B. Appetecchi, G.-T. Kima, M. Montaninoa, M. Carewskaa, R. Marcilla, D. Mecerreyes and I. D. Meatza, J. Power Sources, 2010, 195, 3668-3675; (b) R. A. DiLeo, A. C. Marschilok, K. J. Takeuchi and E. S. Takeuchi, J. Electrochem. Soc., 2013, 160, A1399-A1405.

30 T. Jiang, M. J. Chollier Brym, G. Dubé, A. Lasia and G. M. Brisard, Surf. Coat. Technol., 2006, 201, 1-9.

31 T. Jiang, M. J. Chollier Brym, G. Dubé, A. Lasia and G. M. Brisard, Surf. Coat. Technol., 2006, 201, 10-18.

32 J. J. Auborn and Y. L. Barberio, J. Electrochem. Soc., 1985, 132, 598-601.

33 P. K. Lai and M. Skyllas-Kazacos, J. Electroanal. Chem. Interfacial Electrochem., 1988, 248, 431-440.

34 P. Peljo and H. H. Girault, Energy Environ. Sci., 2018, 11, 2306-2309.

35 H. Wang, S. Gu, Y. Bai, S. Chen, N. Zhu, C. Wu and F. Wu, J. Mater. Chem. A, 2015, 3, 22677-22686.

36 G. Kresse and J. Furthmüller, Phys. Rev. B: Condens. Matter Mater. Phys., 1996, 54, 11169.

37 Y. Chen, F. Peng, Y. Yan, Z. Wang, C. Sun and Y. Ma, J. Phys. Chem. C, 2013, 117, 13879.

38 P. E. Blöchl, Phys. Rev. B: Condens. Matter Mater. Phys., 1994, 50, 17953-17979.

39 J. P. Perdew, K. Burke and M. Ernzerhof, Phys. Rev. Lett., 1996, 77, 3865-3868.

40 S. Grimme, J. Antony, S. Ehrlich and H. A. Krieg, J. Chem. Phys., 2010, 132, 154104.

41 Y. Baskin and L. Meyer, Phys. Rev., 1955, 100, 544.

42 V. S. Bernales, A. V. Marenich, R. Contreras, C. J. Cramer and D. G. Truhlar, J. Phys. Chem. B, 2012, 116, 9122-9129.

43 W. J. Hehre, R. Ditchfield and J. A. Pople, J. Chem. Phys., 1972, 56, 2257-2261.

44 R. Krishnan, J. S. Binkley, R. Seeger and J. A. Pople, J. Chem. Phys., 1980, 72, 650-654.

45 M. J. Frisch, G. W. Trucks, H. B. Schlegel, G. E. Scuseria, M. A. Robb, J. R. Cheeseman, G. Scalmani, V. Barone, B. Mennucci, G. A. Petersson, H. Nakatsuji, M. Caricato, X. Li, H. P. Hratchian, A. F. Izmaylov, J. Bloino, G. Zheng, J. L. Sonnenberg, M. Hada, M. Ehara, K. Toyota, R. Fukuda, J. Hasegawa, M. Ishida, T. Nakajima, Y. Honda, O. Kitao, H. Nakai, T. Vreven, J. A. Montgomery Jr, J. E. Peralta, F. Ogliaro, M. Bearpark, J. J. Heyd, E. Brothers, K. N. Kudin, V. N. Staroverov, R. Kobayashi, J. Normand, K. Raghavachari, A. Rendell, J. C. Burant, S. S. Iyengar, J. Tomasi, M. Cossi, N. Rega, J. M. Millam, M. Klene, J. E. Knox, J. B. Cross, V. Bakken, C. Adamo, J. Jaramillo, R. Gomperts, R. E. Stratmann, O. Yazyev, A. J. Austin, R. Cammi, C. Pomelli, J. W. Ochterski, R. L. Martin, K. Morokuma, V. G. Zakrzewski, G. A. Voth, P. Salvador, J. J. Dannenberg, S. Dapprich, A. D. Daniels, O. Farkas, J. B. Foresman, J. V. Ortiz, J. Cioslowski and D. J. Fox, Gaussian 09, Revision D.01, Gaussian, Inc., Wallingford CT, 2009.

46 H. M. A. Abood, A. P. Abbott, A. D. Ballantyne and K. S. Ryder, Chem. Commun., 2011, 47, 3523-3525. 
47 H. Li, Y. Chang, W. Zhu, W. Jiang, M. Zhang, J. Xia, S. Yin and H. Li, J. Phys. Chem. B, 2015, 119, 5995-6009.

48 Y. Zheng, K. Dong, Q. Wang, J. Zhang and X. Lu, J. Chem. Eng. Data, 2013, 58, 32-42.

49 J. B. Goodenough and Y. Kim, Chem. Mater., 2010, 22, 587-603.

50 G. Baysinger, Lev I. Berger, R. N. Goldberg, H. V. Kehiaian, K. Kuchitsu, G. Rosenblatt, D. L. Roth and D. Zwillinger, CRC Handbook of Chemistry \& Physics, CRC Press, London, 73rd edn, 1992-1993.

51 J. Hölzl and F. K. Schulte, Springer Tracts in Modern Physics, Springer, Berlin, Heidelberg, 2006, vol. 85, DOI: 10.1007/ BFb0048919.

52 S. Trasatti, Pure Appl. Chem., 1986, 58, 955-966.

53 B. Vestergaard, N. J. Bjerrum, I. Petrushina, H. A. Hiuler, R. W. Berg and M. Begtrup, J. Electrochem. Soc., 1993, 140, 3108-3113.

54 G. E. Gray, J. Winnick and P. A. Kohl, J. Electrochem. Soc., 1996, 143, 3820.

55 Z. Lv, M. Han, J. Sun, L. Hou, H. Chen, Y. Li and M.-C. Lin, J. Power Sources, 2019, 418, 233-240.

56 H. Sun, W. Wang, Z. Yu, Y. Yuan, S. Wang and S. Jiao, Chem. Commun., 2015, 51, 11892-11895.
57 F. Weinhold and C. Landis, Chem. Educ. Res. Pract., 2001, 2, 91-104.

58 N. Canever, N. Bertrand and T. Nann, Chem. Commun., 2018, 54, 11725-11728.

59 A. P. Abbott, ChemPhysChem, 2005, 6, 2502-2505.

60 P. Bonhôte, A.-P. Dias, N. Papageorgiou, K. Kalyanasundaram and M. Gra1tzel, Inorg. Chem., 1996, 35, 1168-1178.

61 K. R. Harris, J. Phys. Chem. B, 2018, 122, 10964-10967.

62 A. P. Abbott, ChemPhysChem, 2004, 5, 1242-1246.

63 C. Yang, S. Wang, X. Zhang, Q. Zhang, W. Ma, S. Yu and G. Sun, J. Phys. Chem. C, 2019, 123, 11522-11528.

64 G. Zhu, M. Angell, C.-J. Pan, M.-C. Lin, H. Chen, C.-J. Huang, J. Lin, A. J. Achazi, P. Kaghazchi, B.-J. Hwang and H. Dai, RSC Adv., 2019, 9, 11322-11330.

65 M. Angell, G. Zhu, M.-C. Lin, Y. Rong and H. Dai, Adv. Funct. Mater., 2020, 30, 1901928.

66 K. V. Kravchyk, S. Wang, L. Piveteau and M. V. Kovalenko, Chem. Mater., 2017, 29, 4484-4492.

67 Z. Yu, J. Tu, C. Wang and S. A. Jiao, ChemistrySelect, 2019, 4, 3018-3024.

68 P. Bhauriyal, A. Mahata and B. Pathak, Phys. Chem. Chem. Phys., 2017, 19, 7980-7989. 